\title{
In vitro Release Kinetic Study of Theophylline from Eudragit RS PO and Eudragit RL PO Matrix Tablets
}

\author{
Apurba Sarker Apu, Atiqul Haque Pathan, Golam Kibria and Reza-ul J alil \\ Department of Pharmaceutical Technology, Faculty of Pharmacy, University of Dhaka, \\ Dhaka-1000, Bangladesh
}

\begin{abstract}
The aim of the present study was to investigate the release kinetics of theophylline from permeable acrylic polymer matrix tablets. Matrix tablets were prepared by direct compression method using Eudragit RS PO and Eudragit RL PO. Two batches of matrix tablets were prepared. Only Eudragit RS PO was used in the first batch, and in the second batch both Eudragit RS PO and Eudragit RL PO were used as the rate retarding polymers in different proportions. The variation of hardness was insignificant in batches. Drug release was investigated by using USP basket method and the results of release rates were analyzed by using correlation coefficient value of Zero order release plot \& Higuchi plot and exponent value of Bi-exponential release profile. Theophylline tablets having only Eudragit RS PO showed comparatively slow release but release rate improved significantly as seen in formulations containing Eudragit RL PO and Eudragit RS PO. It was also revealed that, in all cases the release of theophylline followed mixed release kinetics where Zero order release kinetics was predominant.
\end{abstract}

Key words: Sustained release, matrix tablet, theophylline, acrylic polymers, eudragit, release rate, dissolution, hardness.

\section{INTRODUCTION}

Pharmaceutical preparations with controlled release characteristics have been introduced in the early 1950s. In recent years, considerable attention has been focused on the development of sustained release dosage forms for various advantages, e.g., to deliver drug at desired rate to achieve, maintain a constant drug blood level and to reduce side effects over the conventional dosage forms. ${ }^{1}$ In reality, the scientists are attempting to take the control of the medication away from the patient, and to some extent the physician, and to place it in the drug delivery system. ${ }^{1}$

Correspondence to:

Reza-ul Jalil

Tel: +880-2-9661900-73 (Ext-8179), Fax: +88-02-8615583

E-mail: raju1559@yahoo.com

Dhaka Univ. J. Pharm. Sci. 8(1): 1-6, 2009 (June)
Drug release from the matrix tablets can be strongly influenced by the proportion of matrix forming polymer and the dimensions and geometry of the tablets. ${ }^{2}$ The matrix tablets or matrices describe a tablet in which the drug is embedded in a skeleton of non dissolving material. It needs simply direct compression of blended drugs, retardant materials and additives to form tablets. It is one of the low cost and least complicated approaches to manufacture sustained release dosage form that consist of drug dispersed in a polymer, the polymer playing the role of a matrix. ${ }^{3}$

In this research work, theophylline was taken as the model drug to investigate numerous formulations of matrix tablets using Eudragit RS PO and Eudragit RL PO acrylic polymers. Eudragit RS and Eudragit $\mathrm{RL}$ have been used as rate retarding polymers for more than a decade. But their powder forms, Eudragit 
RL PO and RS PO have free flowing and direct compressible properties unlike other forms. ${ }^{4}$

Theophylline is a bronchodilator used in the symptomatic treatment of mild bronchial asthma and reversible bronchospasm acts by inhibiting cyclic nucleotide phosphodiesterase. ${ }^{5}$ It has a narrow therapeutic index which requires regular monitoring of serum theophylline concentrations. ${ }^{6}$ Therefore, sustained release forms of theophylline are used to avoid adverse effects and promote its more efficient use. The benefits of sustained release theophylline preparations have been demonstrated by several researchers. ${ }^{7}$

The objective of this research work was to prepare and kinetically evaluate the effect of Eudragit RS PO and Eudragit RL PO grades on the release rate of theophylline from matrix tablets as well as the role of hardness on theophylline release kinetics.

\section{MATERIALS AND METHODS}

Theophylline was a kind gift from Square Pharmaceuticals Limited, Bangladesh. Eudragit RL PO and Eudragit RS PO (BASF, Germany), Ludipress LCE (BASF, Germany), Magnesium stearate (BDH, UK), Talc (BDH, UK), Aerosil (BASF, Germany) and all other solvents and chemicals used were of reagent grade.

Preparation of theophylline matrix tablets. For the preparation of matrix tablets, theophylline in combination with different excipients (corresponding to formulation code) were blended by laboratory designed small drum blender machine for 10 minutes.
The formulations of matrix tablets with their codes are presented in Table 1. Matrix prepared with Eudragit RS PO coded as 'A' series and with Eudragit RS PO and Eudragit RL PO coded as 'B' series. The appropriate amount of mixture was then compressed using a "Perkin-Elmer" laboratory hydraulic press equipped with 13-mm flat faced punch and die set. The compression force and compression time were 5 ton and 20 seconds respectively. The tablets were kept in desiccator until use.

Evaluation of tablets. Study of hardness: For each formulation, the hardness of 2 tablets was determined using electronic hardness tester (Erweka TBH 28, Germany). The average crushing strengths (hardness values) were determined and the data is presented in Table 2.

In vitro release studies: Dissolution studies were carried out on "Electrolab" tablet dissolution tester USP with rotation of $50 \mathrm{rpm}$ at $37^{0} \mathrm{C}\left( \pm 0.5^{\circ} \mathrm{C}\right)$ using $1 \mathrm{~L}$ distilled water as dissolution medium in each vessel. $6 \mathrm{ml}$ sample was taken by filtration at regular intervals of 5, 10, 20, 30, 60, 120, 180, 240, 300, 360, 420 and 480 minutes in case of matrix tablets with Eudragit RS PO only and at regular intervals of 5, 10, $20,30,60,120,180,240,300,360,420,480,600$ and 720 minutes in case of matrix tables with both Eudragit RS PO and Eudragit RL PO matrix tablets. After each sampling the volume loss was added up by transferring water in each vessel. Absorbance was measured by using spectrophotometer (Shimadzu UV-1200, Japan) at $271 \mathrm{~nm}$.

Table 1. Composition of different formulation (mg) of matrix tablets.

\begin{tabular}{lccccccccccc}
\hline & \multicolumn{10}{c}{ Formulation code } \\
\hline Ingredients & A1 & A2 & A3 & A4 & A5 & B1 & B2 & B3 & B4 & B5 & B6 \\
\hline Theophylline & 250 & 250 & 250 & 250 & 250 & 400 & 400 & 400 & 400 & 400 & 400 \\
Ludipress LCE & 0 & 50 & 100 & 150 & 200 & 100 & 100 & 100 & 100 & 100 & 100 \\
Eudragit RS PO & 400 & 350 & 300 & 250 & 200 & 500 & 450 & 400 & 350 & 300 & 250 \\
Eudragit RL PO & - & - & - & - & - & 0 & 50 & 100 & 150 & 200 & 250 \\
Talc & 3 & 3 & 3 & 3 & 3 & 8 & 8 & 8 & 8 & 8 & 8 \\
Mg-stearate & 2 & 2 & 2 & 2 & 2 & 4 & 4 & 4 & 4 & 4 & 4 \\
Aerosil & 1 & 1 & 1 & 1 & 1 & 3 & 3 & 3 & 3 & 3 & 3 \\
Total weight & 656 & 656 & 656 & 656 & 656 & 1015 & 1015 & 1015 & 1015 & 1015 & 1015 \\
\hline
\end{tabular}




\section{RESULTS AND DISCUSSION}

Theophylline matrix tablets were prepared by using Eudragit RS PO and Eudragit RL PO as sustained release polymer after simple dry mixing of the proposed ingredients (Table 1) and then the hardness and the dissolution behavior of matrix tablets were observed.

The hardness of the Eudragit RS PO matrix tablets were varied at same pressure ranging from $255.99 \pm 28.988 \mathrm{~N}$ to $302.98 \pm 7.014 \mathrm{~N}$ (Table 2). The matrix tablets of A3, having Ludipress LCE and Eudragit RS PO in the ratio of 1:3 showed highest value of hardness. Again, the hardness of Eudragit RS PO and Eudragit RL PO matrix tablets were varied from $238.481 \pm 0.490 \mathrm{~N}$ to $329.370 \pm 3.384 \mathrm{~N}$. It was found that the hardness was highest for the matrix tablets B6 containing 50\% Eudragit RS PO and 50\% Eudragit RL PO (Table 2).

Table 2. Hardness of Eudragit RS PO matrix tablets \& Eudragit RS PO and Eudragit RL PO combination matrix tablets.

\begin{tabular}{cc}
\hline $\begin{array}{c}\text { Formulation } \\
\text { code }\end{array}$ & $\begin{array}{c}\text { Average hardness } \\
\text { Newton }(\mathrm{N})( \pm \mathrm{SD})\end{array}$ \\
\hline A1 & $300.53 \pm 8.485$ \\
A2 & $285.18 \pm 7.848$ \\
A3 & $302.98 \pm 7.014$ \\
A4 & $286.99 \pm 38.994$ \\
A5 & $255.99 \pm 28.988$ \\
B1 & $308.52 \pm 16.480$ \\
B2 & $238.48 \pm 0.490$ \\
B3 & $280.47 \pm 15.499$ \\
B4 & $327.51 \pm 0.539$ \\
B5 & $324.51 \pm 0.490$ \\
B6 & $329.37 \pm 3.384$ \\
\hline
\end{tabular}

It is well established that the hardness of the tablet could markedly affect the release rate of drug. ${ }^{8}$ Usually, an increase in hardness of a tablet is accompanied by a decrease in release rate, due to a decrease in porosity of the tablet. ${ }^{9}$ As there is no significant change in the hardness of matrix tablets with the change of sustained release polymer, the release rate of theophylline from matrix tablets is not influenced by tablet hardness.

To know the mechanism of drug release from these formulations, the data were treated according to Zero order ${ }^{10}$ (cumulative amount of drug released vs. time) and Highuchi's ${ }^{11}$ (cumulative percentage of drug released vs. square root of time) model. Dissolution data were also fitted according to the well-known exponential equation, which is often used to describe the drug release behavior from polymeric systems introduced by Peppas et al. ${ }^{12}$

An ideal matrix formulation should contain polymers and diluents at amounts as little as possible, as well as releasing its content in a sustained release profile over a reasonable length of time, and preferably with a Zero order kinetic. ${ }^{13}$

It was found that in the Eudragit RS PO matrix tablet, with the increase of Ludipress LCE and decrease of Eudragit RS PO, the release rate increased slowly and linearly in water media (Figure 1). The release rate was found to be the highest ( $81 \%$ approximately in 8 hours) when equal amount of Eudragit RS PO and Ludipress LCE used in the formulation.

Table 3. Drug release parameters from Eudragit RS PO matrix tablets \& Eudragit RS PO and Eudragit RL PO combination matrix tablets.

\begin{tabular}{|c|c|c|c|}
\hline \multirow{2}{*}{$\begin{array}{l}\text { Formulation } \\
\text { code }\end{array}$} & Zero order & Higuchi & Diffusional \\
\hline & $\begin{array}{c}\text { Correlation } \\
\text { coefficient } \\
\left(r^{2}\right)\end{array}$ & $\begin{array}{c}\text { Correlation } \\
\text { coefficient } \\
\left(\mathrm{r}^{2}\right)\end{array}$ & $\begin{array}{l}\text { Exponent } \\
\text { (n) }\end{array}$ \\
\hline A1 & 0.9345 & 0.9916 & 0.4575 \\
\hline A2 & 0.9438 & 0.9955 & 0.5435 \\
\hline A3 & 0.9765 & 0.9860 & 0.6407 \\
\hline A4 & 0.9959 & 0.9600 & 0.8258 \\
\hline A5 & 0.9963 & 0.9369 & 0.9034 \\
\hline B1 & 0.9066 & 0.9954 & 0.5215 \\
\hline B2 & 0.9522 & 0.9957 & 0.5771 \\
\hline B3 & 0.9522 & 0.9797 & 0.6016 \\
\hline B4 & 0.9877 & 0.9745 & 0.6486 \\
\hline B5 & 0.9929 & 0.9474 & 0.7026 \\
\hline B6 & 0.9937 & 0.9481 & 0.7389 \\
\hline
\end{tabular}


High correlation coefficient was observed (Table 3) in Higuchi plot rather than Zero order in case of A1, A2 and A3 formulation. Thus the drug release was proportional to the square root of time, indicating that the drug release is diffusion controlled. But A4 and A5 formulation follows Zero order release model as the correlation coefficient values greater than 0.99 . The Zero order rate describes the systems where the drug release rate is independent of its concentration.

In most of the cases it was revealed that the release kinetics of theophylline from the matrix tablet appeared to follow the mixed release kinetics of Zero order $\left(r^{2}>0.99\right)$ and Higuchi's release kinetics $\left(r^{2}>\right.$ 0.95 ) but Zero order release kinetics predominates, which complies the almost straight lines fitness of the data. The formulation which had high concentration of the Eudragit RS PO followed Higuchi release but decrease of Eudragit RS PO and increase of Ludipress LCE in the formulation followed Zero order release. This explains why the drug diffuses at a comparatively slower rate as the distance for diffusion increases, which is referred to as square root kinetics (Higuchi's kinetics).
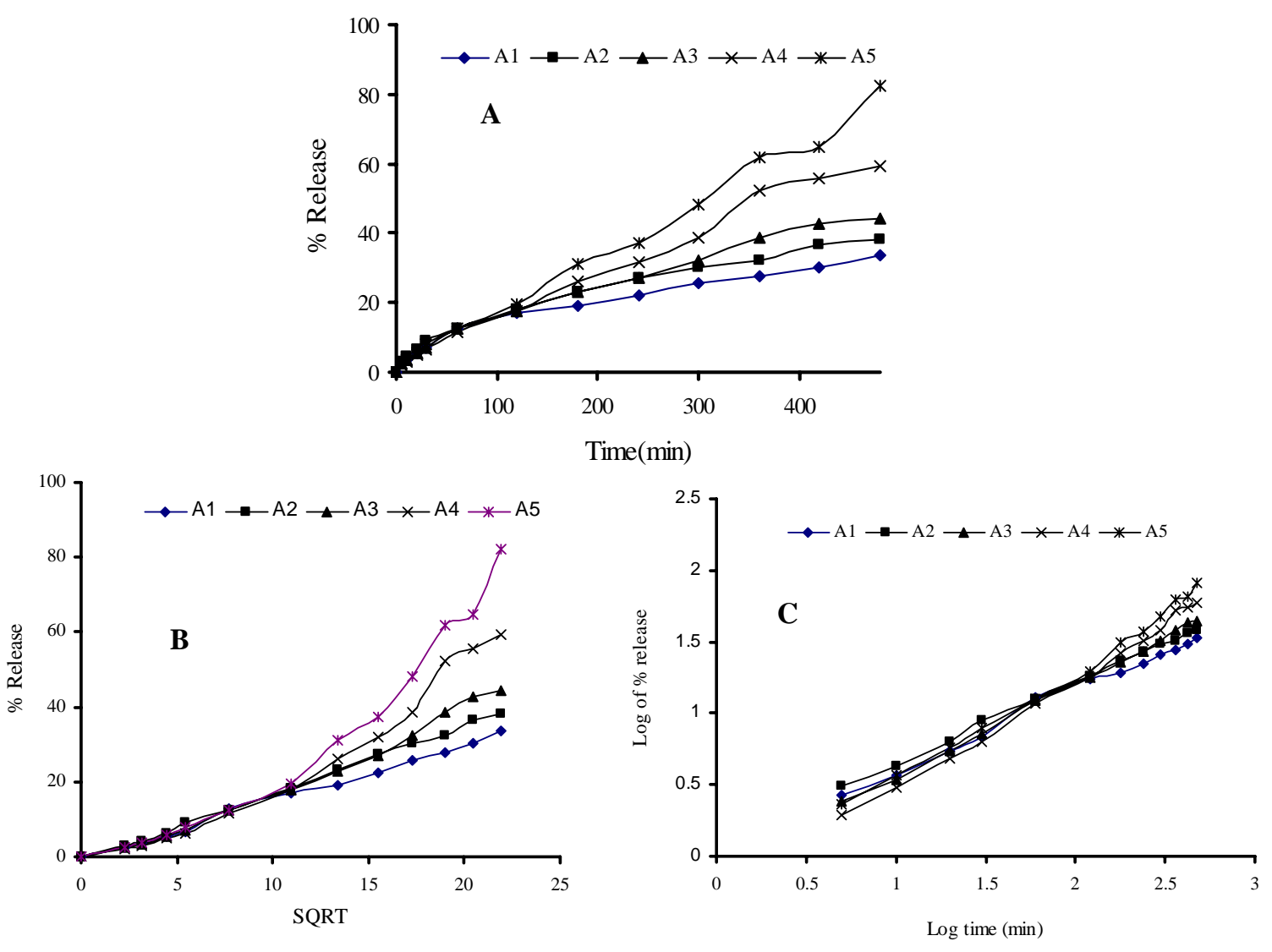

Figure 1. Release profile of Theophylline from Eudragit RS PO matrix tablets. A: Zero order plot, B: Higuchi plot, C: Bi exponential plot.

The diffusional exponent of A1, A2, A3, and A4 (0.4575-0.8258) indicates non-fickian type of release mechanism which refers to the drug release by coupling of Fickian diffusion and polymer matrix relaxation- so-called anomalous diffusion and may indicate that the drug release is controlled by more than one process (Table 3). The diffusional exponent of A5 (0.9034) indicates super class II transport. In super class II transport, the release curve is linear for an exponential function of the release upon the time.

In Eudragit RS PO and Eudragit RL PO matrix tablets, the total percentage of polymer was kept the same but their ratio was varied with the formulations. With the increase of amount of Eudragit RS PO, the 
amount of Eudragit RL PO was decreased in the formulations so as to keep the total percentage of the polymers used in the formulation unchanged (Table 1).

It was also found that the percentage of Eudragit RL PO was increased up to $50 \%$ of the total polymer in the Eudragit RS PO and Eudragit RL PO matrices, the release rate increased slowly and linearly (figure 2). The release rate was found to be the highest (85\% approximately in 12 hours) when Eudragit RL PO constituted $40 \%$ of the total polymer used in the formulation.

High correlation coefficient was observed (Table 3) in Higuchi plot rather than Zero order in case of B1, B2 and B3 formulation. Thus the drug release was proportional to the square root of time, indicating that the drug release is diffusion controlled. But B4, B5 and B6 formulation followed Zero order release model as the correlation coefficient values greater than 0.99 .
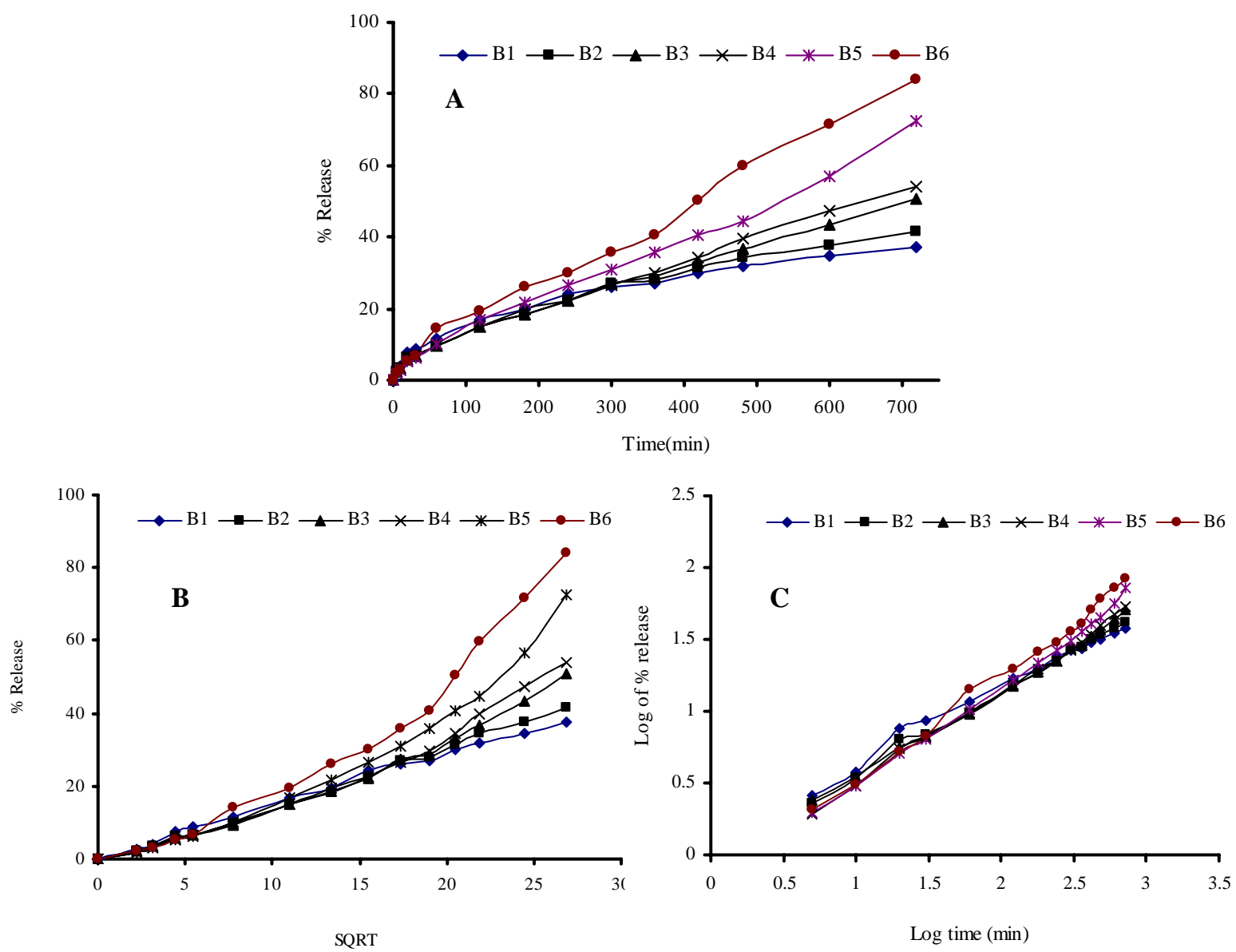

Figure 2. Release profile of Theophylline from Eudragit RS PO and Eudragit RL PO matrix tablets. A: Zero order plot, B: Higuchi plot, C: Bi exponential plot.

In most of the cases it was revealed that the release kinetics of theophylline from the matrix tablet appeared to follow the mixed release kinetics of Zero order $\left(r^{2}>0.99\right)$ and Higuchi's release kinetics $\left(r^{2}>\right.$ 0.95). The percentage of Eudragit RL PO increasing but decreasing the percentage of Eudragit RS PO, exhibiting that inclusion of the highly permeable polymer Eudragit RL PO increases the porosity of the matrix and, thus, accelerates the drug release, as shown by Das and Das (1998). ${ }^{14}$ This may also due to the fact that Eudragit RL PO swells more than Eudragit RS PO. 
The diffusional exponent of B1, B2, B3, B4, B5 and B6 (0.5215-0.7389) indicates non-fickian type of release mechanism which refers to the drug release by coupling of Fickian diffusion and polymer matrix relaxation. Fassihi and Ritschel observed similar results with a matrix tablet of theophylline with an $n$ value of $0.7 .^{15}$

The fact was expected that diffusion is the preferential mechanism of drug release from this kind of matrices. On the other hand, theophylline although being a slight soluble drug, released from matrices occurs by diffusion and not by erosion, as the matrices maintained their original shape from the start to end of dissolution tests.

\section{CONCLUSION}

In the experiment, two new grades of Eudragit polymer like Eudragit RS PO and Eudragit RL PO were used to prepare matrix tablets. It was observed that when only Eudragit RS PO was used in the formulation the release rate was slow but the release rate improved significantly when both Eudragit RS PO and Eudragit RL PO was included in the formulation, due to greater permeability and lesser sustaining property of Eudragit RL PO. There was no significant change in physical property of matrix tablets with the change of sustained release polymer.

\section{Acknowledgement}

The authors wish to thank Square Pharmaceuticals Ltd. (Dhaka, Bangladesh) for providing theophylline. They also thank Essential Drug Company Ltd. (Dhaka, Bangladesh) for providing technical support.

\section{REFERENCES}

1. Aulton, M. E. 2002. Pharmaceutics: The Science of Dosage Form Design. $2^{\text {nd }}$ Edition, Churchill Livingstone, Spain, pp. 289-305.
2. Parojcic, J., Duric, Z., Jovanovic, M., and Ibric, S. 2004. An investigation into the factors influencing drug release from hydrophilic matrix tablets based on novel carbomer polymers. Drug. Deliv. 11, 59-65.

3. Armand, J.Y., Magnard, F., Bouzon, J., Rollet, M., Taverdet, J.L. and Vernaud, J.M. 1987. Modelling of the release of drug in gastric liquid from spheric galenics form with eudragit matrix. Int. J. Pharm. 40, 33-41.

4. Kibbe, A. H. 2000. Handbook of pharmaceutical excipients. $3^{\text {rd }}$ edition, American Pharmaceutical Association, Washington, D.C., pp. 401-406.

5. British Pharmacopoeia (B.P.). London, UK: Stationary Office London; 2004.

6. Goodman, L.S. and Gilman, A.G. (eds.) 1996. The Pharmacological Basis of Therapeutics. $9^{\text {th }}$ Edition, Pergamon Press, New York, pp. 673-682.

7. Ofoefule, S.I. and Chukwu, A. 1999. Use of acryclic and methacrylic acid derivatives as sustained release matrices for theophylline hydrate tablets. Boll. Chim. Farm. 138, 526-30.

8. Capan, Y. 1965. Influence of technological factors on formulation of sustained release tablets. Drug Dev. Ind. Pharm. 15, 927-956.

9. Katikaneni, P.R., Upadrashta, S.M., Neau, S.H. and Mitra, A.K. 1995. Ethylcellulose matrix controlled release tablets of a water-soluble drug. Int. J. Pharm. 123, 119-125.

10. Harland, R., Dubernet, C., Benoit, J.P., and Peppas, N. 1988. A model of dissolution-controlled, diffusional drug release from non-swellable polymeric microspheres. J Control. Rel. 7, 207-215

11. Higuchi, T. 1963. Mechanism of sustained action medication. Theoretical analysis of rate of release of solid drugs dispersed in solid matrices. J. Pharm. Sci. 52, 1145-1149.

12. Ritger, P.L. and Peppas, N.A. 1987. A simple equation for description of solute release II. Fickian and anomalous release from swellable devices. J. Control. Rel. 5, 37-42.

13. Pather, S.I., Russel, I., Syce, J.A. and Neau, S.H. 1998. Sustained release theophylline by direct compression. Part I. Formulation and in vitro testing. Int. J. Pharm. 164, 1-10.

14. Das, S. K. and Das, N. G. 1998. Preparation and in vitro dissolution profile of dual polymer (Eudragit RS 100 and RL 100) microparticles of diltiazem hydrochloride. Journal of Microencapsulation. 15, 445-452.

15. Fassihi, R.A. and Ritschel, W.A. 1993. Multiple layer, direct compression controlled release system: in vitro and in vivo evaluation. J. Pharm. Sci. 82, 750-754. 